\title{
Effect of Slow Expiration With Glottis Opened in Lateral Posture (ELTGOL) on Mucus Clearance in Stable Patients With Chronic Bronchitis
}

\author{
Jocimar Avelar Martins MSc, Armèle Dornelas de Andrade PhD, Raquel Rodrigues Britto PhD, \\ Rovilson Lara MD, and Verônica Franco Parreira PhD
}

\begin{abstract}
BACKGROUND: Slow expiration with glottis opened in lateral posture (ELTGOL, l'expiration lente totale glotte ouverte en infralatéral) has been used in clinical practice to improve mucus clearance from peripheral airways. The purpose of this crossover study was to evaluate the effect of ELTGOL on mucus clearance of right and left lungs, especially of peripheral lung areas, in stable patients with chronic bronchitis. METHODS: Twelve 45-75-year-old patients with chronic bronchitis were studied (10 of whom had mild to moderate COPD according to the Global Initiative for Chronic Obstructive Lung Disease guidelines). Control and ELTGOL interventions were performed on a randomized allocation of subjects. Mucus clearance was measured through 6 posterior scintigraphy images taken with the patient in the right lateral decubitus position 20 (T1), 40 (T2), 60 (T3), 80 (T4), and 120 (T5) min after baseline image (T0). In the control intervention only ventilatory scintigraphy measurements were performed. During ELTGOL the technique was performed after the baseline image (T0). RESULTS: Significant increases in mucus clearance from the peripheral area were found only in the right lung, and were observed at all times during ELTGOL $(P<.05)$ except T1. Significant increases in mucus clearance were observed at all times studied in the total area of the right lung and in the left lung at T1 and T2. For the intermediate area and central areas, results were similar in both lungs. CONCLUSIONS: ELTGOL was efficient in increasing peripheral airway clearance in dependent lung of patients with chronic bronchitis, most of them with mild to moderate COPD. Key words: slow expiration; glottis; lateral posture; ELTGOL; mucus clearance; COPD. [Respir Care 2012;57(3):420-426. (C) 2012 Daedalus Enterprises]
\end{abstract}

\section{Introduction}

Chronic hypersecretion and impaired mucus clearance are some of the pathophysiological changes in chronic

\footnotetext{
Mr Martins is affiliated with the Rehabilitation Sciences Graduation Program, Universidade Federal de Minas Gerais, Belo Horizonte, Minas Gerais, Brazil, and with the Physiotherapy Department, Arnaldo Gavazza Hospital, Ponte Nova, Minas Gerais, Brazil. Dr Dornelas de Andrade is affiliated with the Physiotherapy Department, Universidade Federal de Pernambuco, Recife, Pernambuco, Brazil. Dr Britto and Dr. Parreira are affiliated with the Physiotherapy Department, Universidade Federal de Minas Gerais, Belo Horizonte, Minas Gerais, Brazil. Dr Lara is affiliated with Arnaldo Gavazza Hospital, Ponte Nova, Minas Gerais, Brazil.
}

This research was partly supported by Pro-Reitoria de Pesquisa da Universidade Federal de Minas Gerais, Fundação de Amparo à Pesquisa do Estado de Minas Gerais, and Conselho Nacional de Desenvolvimento Científico e Tecnológico. The authors have disclosed no conflicts of interest. bronchitis and COPD. These conditions are highly prevalent and increasing causes of morbidity and mortality worldwide. ${ }^{1}$ Chronic hypersecretion and impaired mucociliary transport can lead to airway mucus retention. ${ }^{2}$ Infections

\footnotetext{
Mr Martins presented a version of this paper at the 13th Simpósio Internacional de Fisioterapia Respiratoria, held September 6-9, 2006, in Curitiba, Brazil. Dr Dornelas de Andrade presented a version of this paper at the European Respiratory Society Annual Congress, held September 15-19, 2007, in Stockholm, Sweden.

Correspondence: Verônica Franco Parreira, Laboratório de Avaliação e Pesquisa em Desempenho Cardiorrespiratório, Universidade Federal de Minas Gerais, Avenida Antônio Carlos, 6627, 31.270-901, Belo Horizonte, Minas Gerais, Brazil. E-mail: veronica.parreira@pq.cnpq.br.
}

DOI: $10.4187 /$ respcare. 01082 


\section{Mucus Clearance in Stable Patients With Chronic Bronchitis}

of the lower respiratory tract are related to $65 \%$ of COPD exacerbations. ${ }^{3}$ It is important to identify patients who retain airway mucus and take preventive measures to minimize the risk of a pulmonary infection. ${ }^{4}$ It seems that the use of multiple therapeutic strategies can have a positive impact on exacerbation and hospitalization of these patients. ${ }^{1}$

Several therapeutic strategies, including percussion, postural drainage, chest compression, autogenic drainage, and active cycle breathing techniques, are used to improve airway clearance in these patients. ${ }^{5,6}$ ELTGOL (an acronym from the French term "l'expiration lente totale glotte ouverte en infralatéral") can be defined as an active-passive or active technique where the patient is positioned in lateral decubitus and carries out slow expirations from functional residual capacity (FRC) to residual volume with the glottis open. A physiotherapist behind the patient exerts infralateral abdominal pressure and a counter-support pressure in the overlateral lower rib cage. The ELTGOL has been described as a new and efficient maneuver for patients with impaired secretion. ${ }^{7}$ However, studies analyzing ELTGOL have been performed only during exacerbations. ${ }^{8,9}$

The purposes of this study were to evaluate the effects of ELTGOL on mucus clearance, especially in peripheral lung areas, in stable patients with chronic bronchitis, and to compare the efficacy of this technique in both lungs.

\section{Methods}

\section{Patients}

The sample size, calculated by G*Power 3 software (http://www.psycho.uni-duesseldorf.de/abteilungen/aap/ gpower3), was based on a pilot study performed with the first 10 patients. Taking into consideration the level of significance of .05 and the power of 0.80 , the result was a sample between 9 and 12 participants. For this crossover study, patients with chronic bronchitis were enrolled according to the following inclusion criteria: age between 45 and 75 years old, clinical stability in the 3 weeks preceding the study, flow limitation assessed by spirometry according to Global Initiative for Chronic Obstructive Lung Disease $(\mathrm{GOLD})^{2}$ without association to bronchiectasis, and daily cough and expectoration for at least 3 consecutive months in the last 2 years. ${ }^{2}$ The following exclusion criteria were applied: exacerbation during the period of the study, peripheral oxygen saturation lower than $85 \%$ in room air, respiratory rate higher than 35 breaths/min, and difficulty performing procedures. All patients were maintained on their usual medication, ${ }^{10}$ and no chest physiotherapy was performed in the last 48 hours before the interventions. The study was performed between March and October 2006, approved by the hospital ethics com-

\section{QUICK LOOK}

\section{Current knowledge}

Slow expiration with glottis opened in lateral posture (ELTGOL) is used in clinical practice to improve mucus clearance from peripheral airways.

What this paper contributes to our knowledge

ELTGOL was efficient in increasing peripheral airway clearance in dependent lung of patients with chronic bronchitis and concurrent mild to moderate COPD.

mittee, and all patients gave written consent for their participation.

\section{Instruments}

The radioaerosol used was $20 \mathrm{mCi}$ of technetium-99m with diethylene-triamine-pentaacetic acid (TC99m-DTPA) diluted in $3 \mathrm{~mL}$ of $0.9 \%$ physiologic serum. Aerosol flow was maintained at $7 \mathrm{~L} / \mathrm{min}$ and adjusted by oxygen bursts using a jet nebulizer (ST3, NS Medical Devices, São Paulo, Brazil) placed in a lead box (Ultravent, Mallinckrodt Medical; St Louis, Missouri). ${ }^{11}$ A gamma camera (Millennium, General Electric, Madison, Wisconsin) connected to a computer was used to assess the initial regional distribution and subsequent clearance of the radioaerosol particles in the lungs. A posterior matrix of $256 \times 256 \times 16$ was used to record a major part of the lung volume. ${ }^{11}$ Every image was acquired for 2 minutes. ${ }^{10}$

\section{Initial Evaluation}

Patients were surveyed for anthropometric data, age, smoking history, previous pulmonary illness, and daily medication. Respiratory rate, heart rate, and peripheral oxygen saturation were taken. Spirometry (2120, Vitalograph, Buckingham, United Kingdom) was performed, and $\mathrm{FEV}_{1}$ and $\mathrm{FEV}_{1} / \mathrm{FVC}$ were used to classify the severity of patients with COPD. ${ }^{2,12}$ After this evaluation a brief demonstration about ELTGOL was performed with each patient who had been randomly referred (MatLab, MathWorks, Natick, Massachusetts) for either intervention or a control procedure, with a minimum of a week interval between each intervention. The interventions were always performed in the morning by the same physiotherapist. The exams were performed by a nuclear medicine technician and analyzed by a researcher blinded to the interventions.

The radioaerosol inhalation time was $10 \mathrm{~min}$, and the patients were in a seated position wearing a nose clip. Patients were asked to breathe normally, and every $3 \mathrm{~min}$ 


\section{Mucus Clearance in Stable Patients With Chronic Bronchitis}

to breathe slowly and deeply and hold their breath for 3 seconds to enhance the deposition of radioaerosol in the peripheral airways of their lungs. ${ }^{11,13}$ Patients were studied in the supine position with the gamma camera's collimator positioned under their back. ${ }^{11}$

\section{Intervention Control}

The baseline image (T0) was obtained immediately after inhalation. The second, third, fourth, and fifth images were obtained at $20 \mathrm{~min}$ intervals after T0 (T1, T2, T3, T4, respectively). The sixth image (T5) was obtained $40 \mathrm{~min}$ after T4. The study was completed in a total of $120 \mathrm{~min}$. Spontaneous, but not stimulated, coughing was allowed. Patients remained in the right lateral decubitus position during the entire period.

\section{Intervention ELTGOL}

The baseline image (T0) was obtained, as in the control group, after inhalation of the radioaerosol. Immediately after T0, ELTGOL was performed with patients placed in right lateral position to avoid any influence of the stomach on the images. The second, third, fourth, and fifth images were obtained at the same intervals as in the control group, over a total time of $120 \mathrm{~min}$. As with the control group, spontaneous, but not stimulated, coughing was allowed and patients remained in the right lateral decubitus position during the entire period.

Patients were first asked to breathe normally. Then they were asked to breathe slowly from FRC to residual volume, using a mouthpiece to maintain the glottis opened, in order to decrease airway compression. ${ }^{14,15}$ During the slow expiration the physiotherapist performed a slow abdominal compression, similar to a left chest wall compression, to increase lung deflation. ${ }^{7}$

Three series of ELTGOL were performed. Each was composed of 10 slow and deep expirations. Between each series of maneuvers, a 2 minute rest period was allowed. During the rest period, patients remained in the right lateral position. This session lasted exactly $20 \mathrm{~min}$ for all patients. After ELTGOL the same set of images as in the control group (T1, T2, T3, T4 and T5) was obtained.

\section{Measurements}

Measurements were performed on both right and left lungs to analyze the technique effect in the same position of each. Images of lungs were divided into central, intermediate, and peripheral areas. ${ }^{11}$ Using the radioaerosol tracer technique, mucus clearance was measured in all regions of interest (ROI), including the total area. Mucus clearance was assessed by the radioactivity retained as a percentage of the initial activity over time..$^{10,11,13,16-18}$ Fig-

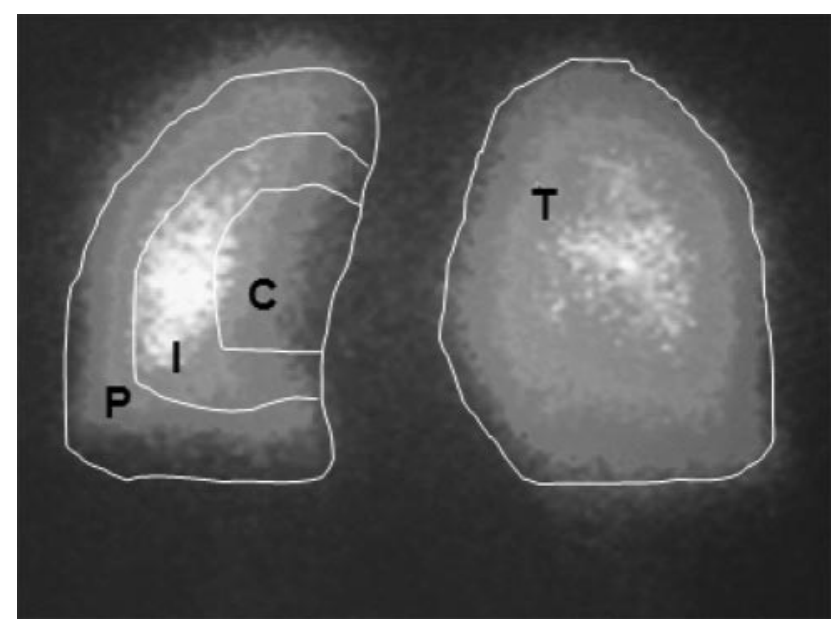

Fig. 1. Delimitation of regions of interest: peripheral $(P)$, intermediate (I), and central $(C)$ in the left lung, and total $(T)$ in the right lung.

ure 1 shows an example of pulmonary deposition of radioaerosol in the ROIs. A comparison between pulmonary depositions in every ROIs was taken to demonstrate the initial deposition percentage. ${ }^{11,19}$

\section{Statistical Analysis}

Distribution analysis was performed using the Kolmogorov-Smirnov test. Data are reported as mean $\pm \mathrm{SD}$. A comparison between pairs of measurements was performed using a paired $t$ test to analyze the retention percentage of radioaerosol activity for each time studied in all ROIs. The significance level $(\alpha)$ was set at .05 for all tests. Statistical analysis was performed with SPSS 13.0 (SPSS, Chicago, Illinois).

\section{Results}

Seventeen patients were selected for this study. Five patients were excluded: 4 had clinical problems between the 2 sessions of the study ( 3 with exacerbation, one with acute myocardial infarction), and one because his data were impossible to analyze.

Twelve patients completed the study: 8 men and 4 women. On average they were $61.76 \pm 8.13$ years old, with a mean body mass indexes of $30.11 \pm 9.26 \mathrm{~kg} / \mathrm{m}^{2}$, a mean respiratory rate of $20 \pm 2$ breaths/min, a mean heart rate of $91 \pm 3$ beats $/ \mathrm{min}$, and a mean peripheral oxygen saturation of $95 \pm 2 \%$. Four patients were smokers, one was a non-smoker, and 7 were ex-smokers; none of the patients was on oxygen therapy. $\mathrm{FEV}_{1}$ was $60.41 \pm 12.51 \%$ and FVC was $87.41 \pm 9.69 \%$, measured as percentages of predicted values. ${ }^{20} \mathrm{FEV}_{1} / \mathrm{FVC}$ was equal to $60.39 \pm 14.31$ 


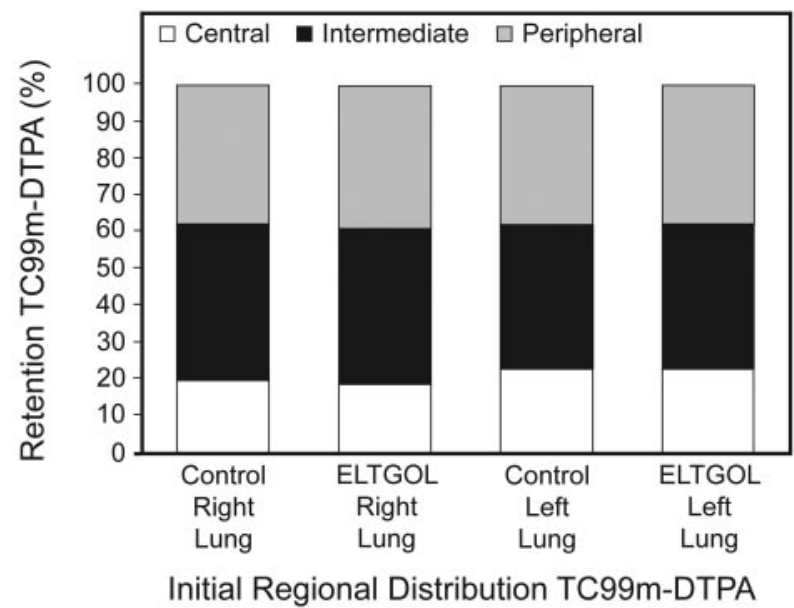

Fig. 2. Baseline regional distribution of the technetium-99m with diethylene-triamine-pentaacetic acid (TC99m-DTPA) in the lung regions during control and ELTGOL.

post-bronchodilator. $^{2}$ All patients were able to perform measurements.

Figure 2 shows the initial mean distribution of deposited radioaerosol in the 3 ROIs after inhalation by patients during control and ELTGOL. No significant differences were observed between the baseline in control and ELTGOL in the right or left lung $(P>.05)$.

Figure 3 shows mucus clearance during control and ELTGOL in the right lung (infralateral) for peripheral, intermediate, central, and total areas. Except for T1, we always observed a significant increase of mucus clearance in the peripheral area during ELTGOL, when compared to control. For the intermediate area a significant increase in mucus clearance during ELTGOL was observed only at T1 and T2. Significant increases were found at T1, T2, T3, and T4 during ELTGOL in the central area, when compared to the control. Total right lung analysis shows a significant increase of mucus clearance during ELTGOL in all comparisons to control.

Figure 4 (next page) shows the mucus clearance during control and ELTGOL in the left lung for the peripheral, intermediate, central, and total areas. There were no significant changes in the peripheral area during ELTGOL, when compared to control. For the intermediate area, a significant increase during ELTGOL was observed only at $\mathrm{T} 1$ and T2. For the central area, significant increases were found at T1, T2, and T3 during ELTGOL, whereas significant increases in the total area of left lung were found only at $\mathrm{T} 1$ and $\mathrm{T} 2$.

\section{Discussion}

The main finding of this crossover study is that ELTGOL significantly increases mucus clearance in the pe-
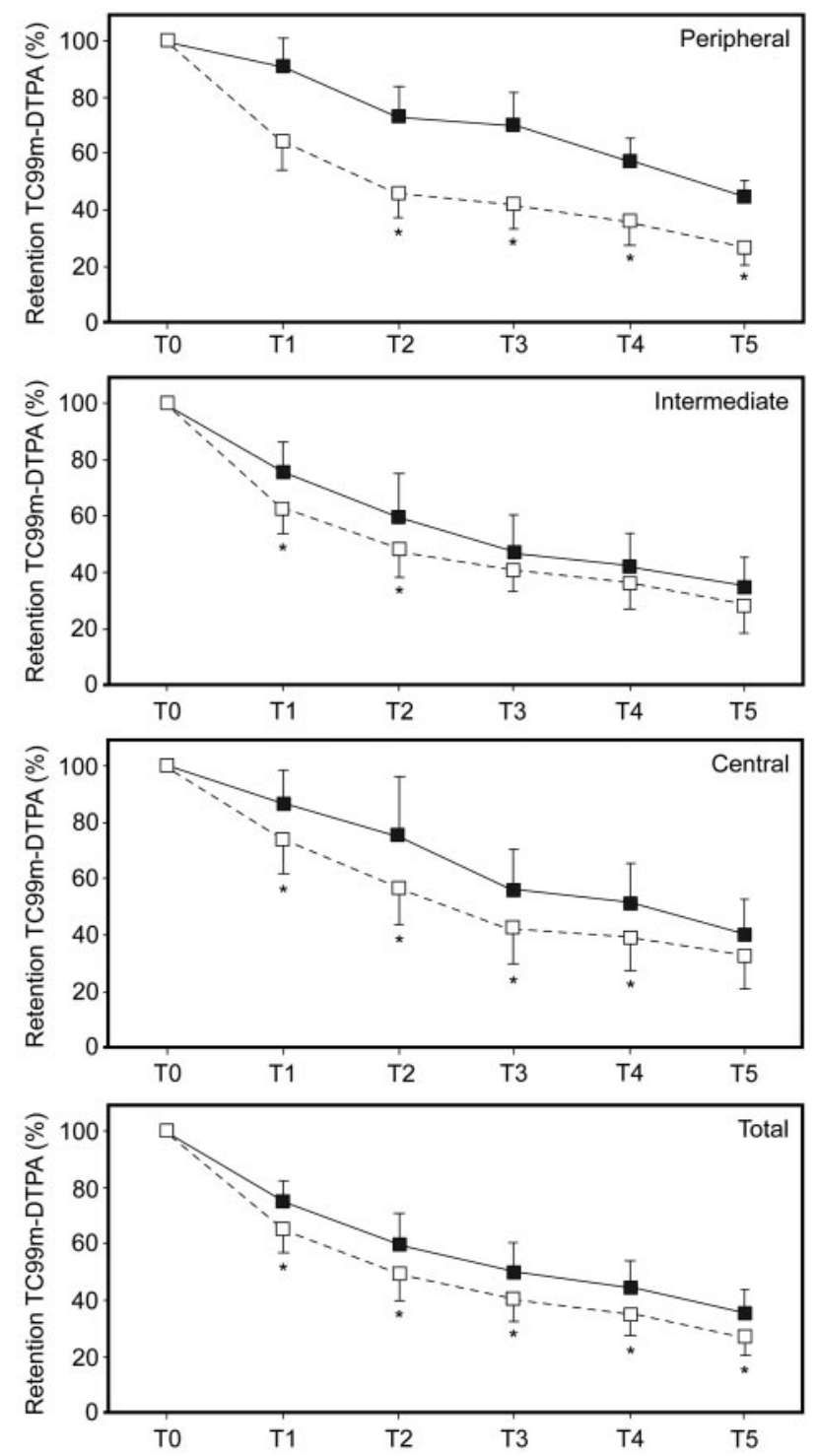

Fig. 3. Right lung. The clearance of the technetium-99m with diethylene-triamine-pentaacetic acid (TC99m-DTPA) is expressed as a percentage of the starting values from the right lung in peripheral, intermediate, central, and total areas. T0 refers to baseline image. T1, T2, T3, T4, and T5 are 20, 40, 60, 80 and $120 \mathrm{~min}$ after T0, respectively. Data are presented as the mean \pm SD. The dotted line refers to ELTGOL, the solid line to control, and * to $P<.05$.

ripheral area of the right lung, the dependent lung, demonstrating the selective aspect of this technique in patients with chronic bronchitis. There were other findings as follows:

- No significant differences were found in the peripheral area of the left lung when compared to control.

- The total area of the right lung showed a significant increase of mucus clearance when the ELTGOL was 

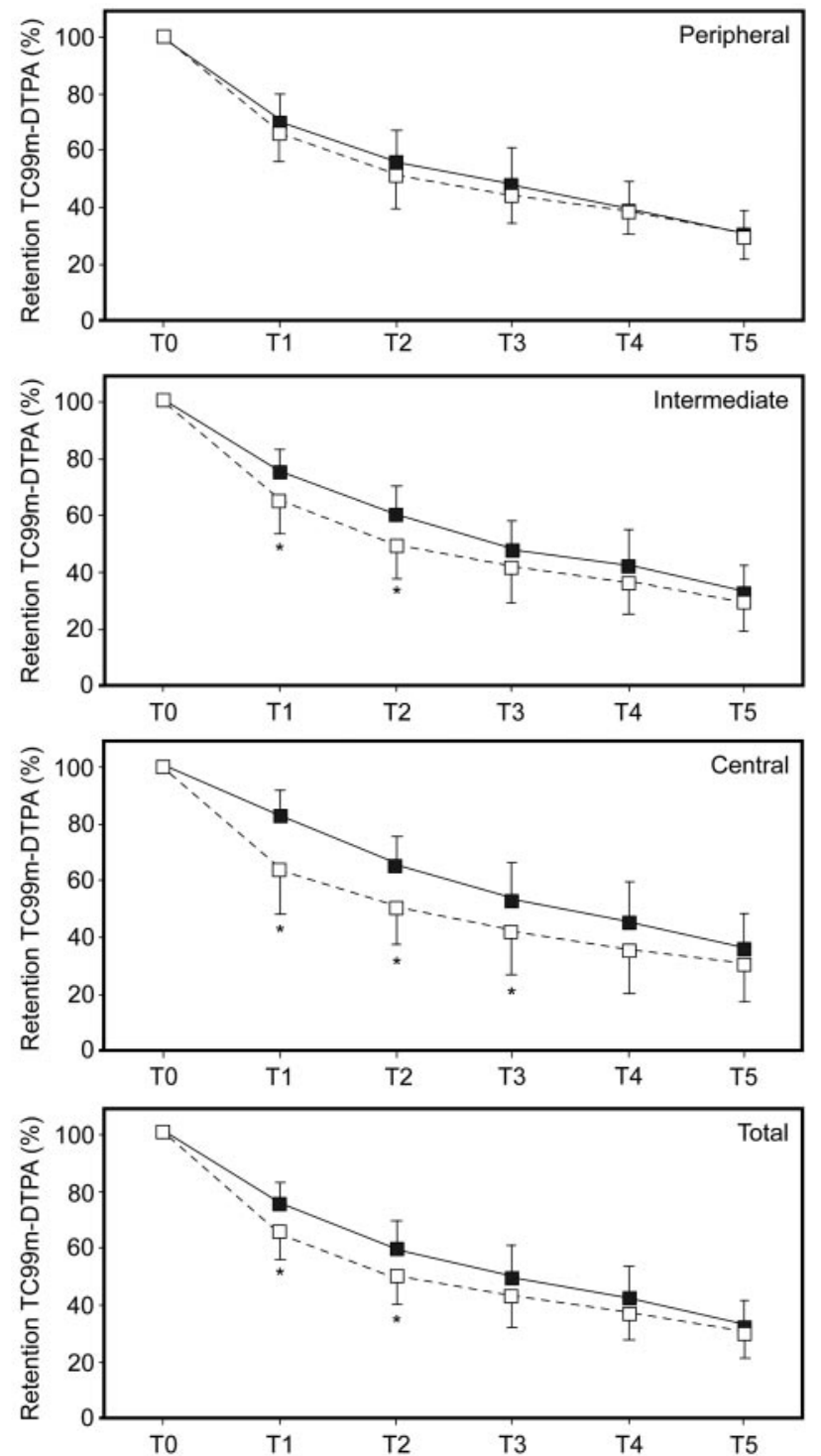

Fig. 4. Left lung. The clearance of the technetium-99m with diethylene-triamine-pentaacetic acid (TC99m-DTPA) is expressed as a percentage of the starting values from the left lung in peripheral, intermediate, central, and total areas. T0 refers to baseline image. T1, T2, T3, T4, and T5 are 20, 40, 60, 80 and 120 min after T0, respectively. Data are presented as mean $\pm \mathrm{SD}$. The dotted line refers to ELTGOL, the continuous line to control, and ${ }^{*}$ to $P<.05$.

compared with control at all of the times studied; however, except $\mathrm{T} 1$ and $\mathrm{T} 2$, no significant differences were observed in the total area of the left lung.

These results clearly showed that the peripheral area of the right lung was responsible for the significant increase of the clearance in its total area, because the increased clearance occurred until $\mathrm{T} 2$ in the intermediate area and until T3 in the central area in both lungs.

These findings show that ELTGOL was efficient at increasing the clearance of mucus in stable patients with chronic bronchitis, especially in the periphery of the right lung (in the infralateral position). These results reinforce the effectiveness of ELTGOL, because significant increases in mucus clearance had begun at T2. In contrast, no significant difference was observed in the peripheral area of the left lung. We observed that the total area of the right lung showed significant increases in mucus clearance at all the times studied when ELTGOL was compared with control. In contrast, significant differences were observed only at $\mathrm{T} 1$ and $\mathrm{T} 2$ in the left lung. Therefore, the clearance in the total area of the right lung seems to be related to the increase of clearance in the peripheral area of the right lung.

The results found in the intermediate and central areas were similar for both the right and left lungs. According to the model proposed by Agnew et al, ${ }^{21}$ mucus follows a route from the peripheral area to the central area of the lungs. Therefore, the mucus depurated from the peripheral area is added to the intermediate area, masking the clearance; this also happens between intermediate and central areas. In central areas, where sufficiently high-speed flow can be obtained, ${ }^{22-24}$ bronchial mucus was probably eliminated through coughing. ${ }^{25}$ The Agnew model reinforces that ELTGOL was responsible for the increased clearance of the peripheral areas. It is possible that these results, observed in both lungs as well as in both interventions, were influenced by cough, which was not stimulated but was allowed. The fact that coughing frequency number was neither controlled nor recorded can be considered a limitation of the study.

The fact that patients were maintained on the same medication throughout the study period can be considered another limitation of our study. Some patients used longacting bronchodilators, but no supplementary medication was used before the measurements, which was verified each day, and measurements were performed at the same time of day in the 2 arms of the study. So, considering that each patient was his or her own control, this probably has no impact on the results.

According to the technique description, ${ }^{7}$ ELTGOL promotes a contra-gravitational mobilization of the mucus in the median and peripheral airways. The choice of lateral decubitus for its performance is due to the search for a better deflation that is favored by 3 forces: gravity, mediastinum weight, and pressure of abdominal viscera on the infralateral lung. A higher deflation of the infralateral lung, achieved through posture associated with a slow expiratory flow obtained in low pulmonary volumes (from FRC) with the use of the mouthpiece, would improve mucus clearance from more distal airways. ${ }^{14}$ The expiratory flow can be optimized in different bronchial generations, and low speed flow will provide a more distal action in the tracheobronchial tree, which is influenced by the gas-liq- 


\section{Mucus Clearance in Stable Patients With Chronic Bronchitis}

uid interaction. ${ }^{26}$ Thus, this slow flow would mobilize mucus in more distal airways. ${ }^{7,25}$

Lannefors and Wollmer ${ }^{10}$ studied mucus clearance in patients with cystic fibrosis, comparing 3 techniques of respiratory physiotherapy: postural drainage, positive expiratory pressure mask, and physical exercise. As in our study, the authors used ventilatory scintigraphy to measure mucus clearance. The authors reported the "surprising finding" that when postural drainage results were analyzed in the 2 lungs, there was a higher mucus clearance in the dependent lung (infralateral) in 7 of 9 studied patients. This finding contradicts the theoretical bases of postural drainage; perhaps this could be explained by the higher mucus clearance in the lung that was in the dependent position.

Bellone et $\mathrm{al}^{8}$ compared the efficacy of 3 techniques of chest physiotherapy, including ELTGOL, on 10 patients with exacerbated chronic bronchitis. The weight of secretions eliminated was evaluated. The results showed that, during the intervention, all 3 techniques were safe and effective in removing secretions. The total quantities of secretions removed after 1 hour of application of the technique were significantly higher when Flutter and ELTGOL were applied, compared to postural drainage. Kodric et $\mathrm{al}^{9}$ recruited 59 patients who were hospitalized for the treatment of exacerbations of COPD, and each was randomly assigned to control or intervention groups. The control group was treated with standard medical therapy, whereas the intervention group was treated with ELTGOL plus medical therapy. A subgroup of patients was followed for 6 months to verify the effects on COPD exacerbations and the need for hospitalizations. The Borg score was significantly improved in the ELTGOL group, and during the follow up the ELTGOL group had numerically fewer exacerbations and less need for hospitalization. Although these studies present methodological differences, ELTGOL demonstrated positive results for each outcome studied.

There was no significant difference in the initial regional radioisotope distribution between the 2 arms of the study in either lung. This ensured equivalent deposition, despite the influence of the size of the inhaled particles and breathing pattern during inhalation in the radioisotope deposition.

Furthermore, a random allocation was used to assign each patient to the control or ELTGOL group. Furthermore, interventions were carried out with a week interval between them. The number of evaluated patients was in accordance with the estimate of the appropriate sample size based on a pilot study. Daily sputum was not measured, because the movement of particles reflects the mucus movement in the airways. Therefore, we believe it is possible to generalize these findings to the studied population.
Mucus clearance has been widely studied to assess the removal of bronchial secretions, and, despite its cost, radioisotope inhalation is the most widely used method. After inhalation, the reduction of radioactivity over time is quantified in sequential images. The transport of mucus from the lungs is assessed by the retention of radioactivity as a percentage of initial radioactivity in the ROIs. ${ }^{27-29}$ Several studies have reported that lung scintigraphy would be the most appropriate instrument to measure the clearance of mucus. ${ }^{10,11,13,24,30}$

Another methodological aspect to be discussed is the 4 smokers included in the study. Some phenomena are associated with acute smoke exposure; these include an autonomic stimulation and cough, which can have different effects on lung mucus transport. ${ }^{28}$ Agnew et al $^{16}$ found no significant difference between mucus clearance in patients with chronic bronchitis, smokers, and ex-smokers. Moreover, the study was performed early in the morning, and the patients were instructed not to smoke before the study. Because the patient served as his own control in our study, this potential bias was minimized.

Functional repercussions related to bronchial mucus can vary greatly. In the most advanced stage, impaired gas exchange is inevitable. ${ }^{31}$ This impairment can reduce the activity and social participation of individuals with hypoxemic COPD. In the future, the long-term effects of ELTGOL, such as exacerbation frequency and intensity, hospitalizations, and quality of life, can be investigated to develop a full understanding of this technique. ${ }^{32}$ We can speculate that the routine use of this technique might contribute to the prevention of infections of the lower respiratory tract in these patients and benefit lung function.

\section{Conclusions}

Our findings suggest that ELTGOL significantly increased mucus clearance in the peripheral area of the infralateral lung in patients with stable chronic bronchitis, most of whom had mild to moderate COPD.

\section{ACKNOWLEDGMENT}

We wish to thank Guy Postiaux PT, Department of Pediatrics, Grand Hôpital de Charleroi, Montignies-sur-Sambre, Belgium, who had encouraged and helped us in the definition of the study protocol and especially for being a pioneer in chest physiotherapy techniques concurring with the improvement of scientific knowledge.

\section{REFERENCES}

1. Celli BR. Update on the management of COPD. Chest 2008;133(6): 1451-1462.

2. Global Initiative for Chronic Obstructive Lung Disease (GOLD). Global strategy for the diagnosis, management, and prevention of chronic obstructive pulmonary disease. GOLD report, updated December $2011 \mathrm{http}: / / \mathrm{www}$.goldcopd.org/guidelines-global-strategyfor-diagnosis-management.html. Accessed December 30, 2011. 


\section{Mucus Clearance in Stable Patients With Chronic Bronchitis}

3. Wang Q, Bourbeau J. Outcomes and health-related quality of life following hospitalization for an acute exacerbation of COPD. Respirol 2005;10(3):334-340.

4. Wedzicha JA, Donaldson GC. Exacerbations of chronic obstructive pulmonary disease. Respir Care 2003;48(12):1204-1213.

5. Langer D, Hendriks E, Burtin C, Probst V, van der Schans C, Paterson $\mathrm{W}$, et al. A clinical practice guideline for physiotherapists treating patients with chronic obstructive pulmonary disease based on a systematic review of available evidence. Clin Rehabil 2009; 23(5):445-462.

6. Bhowmik A, Chahal K, Austin G, Chakravorty I. Improving mucociliary clearance in chronic obstructive pulmonary disease. Respir Med 2009;103(4):496-502.

7. Postiaux G. Kinésithérapie Respiratoire de l'Enfant, 3rd edition. Bruxelles: De boeck \& Larcier; 2003. Book in French.

8. Bellone A, Lascioli R, Raschi S, Guzzi L, Adone R. Chest physical therapy in patients with acute exacerbation of chronic bronchitis: effectiveness of three methods. Arch Phys Med Rehabil 2000;81(5): 558-560.

9. Kodric M, Garuti G, Colomban M, Russi B, Porta RD, Lusuardi M, et al. The effectiveness of a bronchial drainage technique (ELTGOL) in COPD exacerbations. Respirol 2009;14(3):424-428.

10. Lannefors L, Wollmer P. Mucus clearance with three chest physiotherapy regimes in cystic fibrosis: a comparison between postural drainage, PEP and physical exercise Eur Respir J 1992;5(6):748-753.

11. França EE, Dornelas de Andrade AF, Cabral G, Almeida FP, Silva $\mathrm{KC}$, Galindo FV, et al. Nebulization associated with bi-level noninvasive ventilation: analysis of pulmonary radioaerosol deposition. Respir Med 2006;100(4):721-728.

12. Pellegrino R, Veigi G, Brusasco V, Crapo RO, Burgos F, Casaburi $\mathrm{F}$, et al. Imperative strategies for lung function tests. Eur Respir $\mathbf{J}$ 2005;26(5):948-968.

13. Bateman JR, Newman SP, Daunt KM, Pavia D, Clarke SW. Regional lung clearance of excessive bronchial secretions during chest physiotherapy in patients with stable chronic airways obstruction. Lancet 1979;1(8111):294-297.

14. Holland AE, Button BM. Is there a role for airway clearance techniques in chronic obstructive pulmonary disease? Chron Respir Dis 2006;3(2):83-91.

15. Oberwaldner B. Physiotherapy for airway clearance in paediatrics. Eur Respir J 2000;15(1):196-204.

16. Agnew JE, Little F, Pavia D, Clarke SW. Mucus clearance from the airways in chronic bronchitis: smokers and ex-smokers. Bull Eur Physiopathol Respir 1982;18(3):473-484.

17. Konstan MW, Stern RC, Doershuk CF. Efficacy of the Flutter device for airway mucus clearance in patients with cystic fibrosis. J Pediatr 1994;124(5 Pt 1):689-693.
18. Mortensen J, Falk M, Groth S, Jensen C. The effects of postural drainage and positive expiratory pressure physiotherapy on tracheobronchial clearance in cystic fibrosis. Chest 1991;100(5): 1350-1357.

19. Nobre ME, Lopes F, Cordeiro L, Marinho PE, Silva TN, Amorim C, et al. Inspiratory muscle endurance testing: pulmonary ventilation and electromyographic analysis. Respir Physiol Neurobiol 2007; 155(1):41-48.

20. Pereira CAC, Barreto SP, Simões JG, Pereira JWL, Gerstler JG, Nakatami J. Valores de referência para espirometria em uma amostra da população brasileira. J Bras Pneumol 1992;18:10-22. Article in Portuguese.

21. Agnew JE, Bateman JR, Pavia D, Clarke SW. A model for assessing bronchial mucus transport. J Nucl Med 1984;25(2):170-176.

22. Ericsson CH, Svartengren K, Svartengren M, Mossberg B, Philipson $\mathrm{K}$, Blomquist $\mathrm{M}$, et al. Repeatability of airway deposition and tracheobronchial clearance rate over three days in chronic bronchitis. Eur Respir J 1995 Nov;8(11):1886-1893.

23. Mossberg B, Camner P. Mucociliary transport and cough as clearance mechanisms in obstructive lung disease. Eur J Respir Dis 1980; 111(Suppl):18-20.

24. Foster WM. Mucociliary transport and cough in humans. Pulm Pharmacol Ther 2002;15(3):277-282

25. Pryor JA. Physiotherapy for airway clearance in adults. Eur Respir J 1999 Dec;14(6):1418-1424.

26. Schoni MH. Autogenic drainage: a modern approach to physiotherapy in cystic fibrosis. J R Soc Med 1989;82(Suppl 16):32-37.

27. Mossberg B, Camner P. Mucociliary transport and cough as tracheobronchial clearance mechanisms in pathological conditions. Eur J Respir Dis 1980;110(Suppl):47-55.

28. Foster WM, Langenback EG, Bergofsky EH. Disassociation in the mucociliary function of central and peripheral airways of asymptomatic smokers. Am Rev Respir Dis 1985;132(3):633-639.

29. Henkin RE, Boles MA, Dillehay GL, Halama JR, Karesh SM, Wagner RH, et al. Nuclear medicine, 2 edition. New York: Mosby; 1999.

30. van HM, Festen J, Beurskens C, Hankel M, Beekman F, Corstens F. Conventional physiotherapy and forced expiration manoeuvres have similar effects on tracheobronchial clearance. Eur Respir J 1988; 1(8):758-761.

31. Finley TN, Swenson EW, Comroe Jr JH. The cause of arteria hypoxemia at rest in patients with "alveolar-capillary block syndrome". J Clin Invest 1962;41(3):618-622.

32. McCool FD, Rosen MJ. Nonpharmacologic airway clearance therapies: ACCP evidence-based clinical practice guidelines. Chest 2006; 129(1 Suppl):250S-259S. 